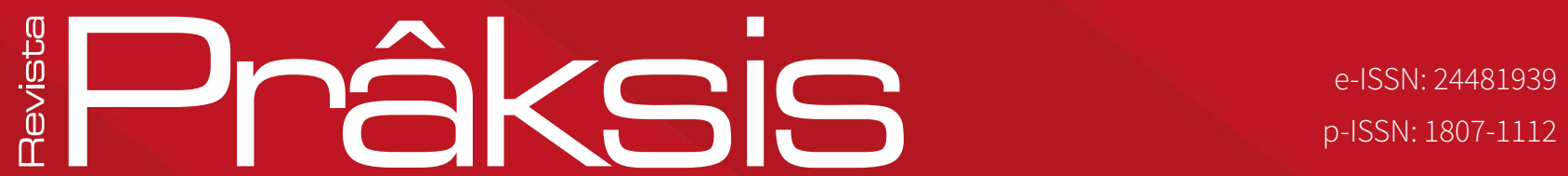

Recebido em: 20 de fevereiro de 2018

Aprovado em: 16 de junho de 2018

Sistema de Avaliação: Double Blind Review

RPR |a. 15 |n. 2 |p. 119-132 | jul./dez. 2018

DOI: https://doi.org/10.25112/rpr.v2i0.1656

\title{
MEMÓRIAS DO ESCRITOR
}

\section{EXILADO NO ROMANCE A ÚLTIMA MORTE DO CORONEL SANTIAGO. DE LUÍs CARDOSO}

\section{MEMORIES OF AN EXILED WRITER IN THE NOVEL THE LAST DEATH OF COLONEL SANTIAGO, BY LUIS CARDOSO}

\section{José Luís Giovanoni Fornos}

Doutor em Lingüística e Letras (Pontifícia Universidade Católica do Rio Grande do Sul/Brasil).

Professor na Universidade Federal do Rio Grande (Rio Grande/Brasil).

E-mail: jlgf@vetorial.net. 


\section{RESUMO}

O presente ensaio examina o romance $A$ última morte do coronel Santiago (2003), do escritor timorense Luís Cardoso, tomando como referência as categorias da memória, da história e do exílio. Com base nos estudos de Paul Ricoeur, desenvolve-se as noções da memória. Em relação aos aspectos que envolvem a condição do sujeito exilado, a análise recorre às reflexões de Edward Said. 0 texto discorre sobre o percurso da personagem principal, um jovem escritor nascido no Timor-Leste exilado em Lisboa, realçando as memórias do mesmo em relação ao seu país de origem, bem como chama atenção para as lembranças do escritor para com seu pai, um defensor do salazarismo.

Palavras-chave: Memória. Exílio. Literatura do Timor-Leste. Luís Cardoso.

\section{ABSTRACT}

This essay examines the novel A última morte do coronel Santiago ("The Last Death of Colonel Santiago") (2003), by the Timorese writer Luis Cardoso, taking as reference the categories of memory, history and exile. The notions of memory are developed based on the studies of Paul Ricoeur. For the analysis of the aspects involving the exiled subject condition, Edward Said's reflections are used. The text discusses the course of the main character, a young writer born in East Timor exiled in Lisbon, whose memories related to home country are highlighted, and attention is drawn to the writer's memories of his father, a defender of Salazarism.

Keywords: Memory. Exile. East Timor literature. Luís Cardoso. 
A obra do escritor Luís Cardoso ${ }^{1}$ se insere num conjunto de romances assinalado pela ideia de transculturação, entrevista como processo social em que diversas culturas se fundem na vida cotidiana em um determinado país ou região. O conceito, extraído de Fernando Ortiz, ${ }^{2}$ foi adaptado para o universo narrativo-literário por Angel Rama. ${ }^{3}$ Segundo Rama (1982), a transculturação aparece como uma mestiçagem cultural, ocorrendo entre a alta cultura e a subalterna. Igualmente, tal categoria pode ser vista como resultado de processos históricos assinalados pelo colonialismo e pelo pós-colonialismo, em que distintos sujeitos se encontram e se enfrentam, desencadeando relações de domínio, exploração e troca.

Os romances de Luís Cardoso se enquadram também às reflexões em torno da memória e da história. É nessa perspectiva, somada às condições do sujeito exilado, que o presente ensaio será desenvolvido, utilizando-se da narrativa $A$ última morte do coronel Santiago, publicada em 2003. Para tanto, recorre-se ao estudo de Paul Ricoeur A memória, a história, o esquecimento (2007), onde o autor se propõe a discutir as aporias da memória, da história e do esquecimento. Uma das preocupações de Ricoeur é compreender a "solução ao problema das relações entre o conhecimento e a prática da história e a experiência da memória viva" (RICOEUR, 2007, p. 146). Ao iniciar tais reflexões, o autor menciona dois conceitos extraídos de Platão e Aristóteles. Para Platão, a memória vincula-se à representação presente de uma coisa ausente (eikón), o que desencadeia discussões em torno do enigma da presença do ausente. Já para Aristóteles, a "memória é do passado" (2007, p. 34). Desta forma, estaria relacionada ao tempo e suas conjecturas com a alteridade.

De acordo com Ricoeur, ainda que a operação historiográfica se constitua em tarefa necessária na ampliação, complementação, correção, e até mesmo na refutação dos testemunhos orais e dos rastros

\footnotetext{
${ }^{1}$ Luís Cardoso de Noronha, nascido em 1958 em Calaico, uma vila no interior do Timor-Leste, é um dos mais importantes escritores timorenses. Luís Cardoso estudou nos colégios missionários de Soibada, Fuiloro e no Seminário de Dare. Em 1974, exila-se em Portugal. Suas principais obras são: Crônica de uma travessia - A época do ai-dik-funam (1997); Olhos de Coruja, Olhos de Gato Bravo (2001); A última morte do Coronel Santiago (2003); Réquiem Para um Navegador Solitário (2006); O ano em que Pigafetta completou a circum-navegação (2013); Para onde vão os gatos quando morrem (2017).

2 Fernando Ortiz aponta na obra Contrapunteo cubano del tabaco e azúcar. "Entendemos que o vocábulo transculturação expressa melhor as diferentes fases do processo transitivo de uma cultura a outra, porque este não consiste apenas em adquirir uma cultura, que é o que a rigor indica o vocábulo anglo-americano aculturação, mas implica também necessariamente a perda ou desligamento de uma cultura precedente, o que poderia ser chamado de uma parcial desaculturação, e, além disso, significa a consequente criação de novos fenômenos culturais que poderiam ser denominados neoculturação" (RAMA, 2001, p. 216).

3 "Aceitando por um momento a descrição que Fernando Ortiz faz das diversas ações que compõem uma transculturação, tentemos ver como se manifestam em uma obra literária de gênero narrativo." Inicialmente, assim se expressa Rama em relação ao conceito. Na sequência, informa que o conceito de transculturação "implicaria, em primeiro lugar, uma parcial desaculturação, que pode mostrar graus muito diferentes e afetar várias áreas do exercício literário, embora comportando em todos os casos perdas obrigatórias em relação aos funcionamentos anteriores, que são abandonados por serem obsoletos" (RAMA, 2001, p. 218).
} 
memorialísticos, a memória aparece como guardiã última do que chama de "dialética constitutiva da preteridade do passado" (2007, p. 505). Se dos acontecimentos não mais existentes, assinalados pela abolição, pode-se dizer que de fato estão acabados e ultrapassados, de outro modo, não se pode escapar de que tenham ocorrido, tomados pela ideia do tendo-sido, isto é, por trazerem em si um caráter originário e indestrutível. ${ }^{4}$ Tal relação dialética entre o não-mais e o tendo-sido revela-se em momento fundamental quando se tomam acontecimentos traumáticos, já que esses não se alicerçam somente na crença, mas se fazem das imagens do passado e do seu testemunho.

$O$ trabalho desenvolvido por Ricoeur procura responder aos grandes crimes do século XX, dentre os quais a Shoah. Com base neles, pensa a ideia de perdão e como acioná-la diante do horror proporcionado pelos genocídios. Para tanto, discorre longamente acerca da categoria memória e sua importância na constituição da operação historiográfica. Ao fazê-lo, traz o pensamento filosófico desde as concepções gregas acerca do tema, em especial, Platão e Aristóteles, passando pela tradição do olhar interior, com Santo Agostinho e John Locke, fixando em boa parte do seu estudo na fenomenologia Husserliana, em que discorre sobre os conceitos de retenção/percepção primária e secundária. Procura igualmente pensar a memória enquanto sintoma neurológico e ético-político, mostrando seus usos e abusos.

Na sequência do estudo, volta-se para o olhar exterior da memória quando recorre ao pensamento de Maurice Halbwachs, que expõe o caráter coletivo da memória. Para lembrarmos, precisa-se necessariamente dos outros, diz Halbwachs. Logo, é com base na ideia de coletividade que se desenvolve as memórias individuais. Desta forma, as primeiras lembranças são aquelas compartilhadas. São as lembranças comuns que nos possibilitam afirmar que jamais estamos sós. Para Halbwachs,

A rememoração pessoal está situada na encruzilhada das redes de solidariedades múltiplas em que estamos envolvidos. Nada escapa à trama sincrônica da existência social atual, é da combinação desses diversos elementos que pode emergir aquela forma que chamamos lembrança, porque a traduzimos em uma linguagem. Assim, a consciência jamais está encerrada em si mesma, não é vazia nem solitária. Somos arrastados em inúmeras direções, como se lembrança fosse uma baliza que permitisse nos situarmos em meio da variação constante dos contextos sociais e da experiência coletiva histórica (2003, p. 13).

\footnotetext{
${ }^{4}$ Em oposição à total abertura da potencialidade verbal da estruturação poética da história, é necessária, de acordo com Ricoeur, que "certa arbitrariedade tropológica não faça esquecer a espécie de pressão que o acontecimento passado exerce sobre o discurso histórico por meio de documentos conhecidos, exigindo dele uma retificação sem fim" (RICOEUR, 1997, p. 259).
} 
A episteme histórica é assinalada pela operação historiográfica. Predominam múltiplas fases a começar pelo testemunho como prática para tal operação, culminando nas análises arquivísticas em que há uma permanente interrogação aos documentos erigidos ao longo do tempo. Segue com a construção de arquivos, passando pela explicação e compreensão dos fenômenos arquivados. A fase final é constituída pela escrita. Segundo Ricoeur, a história é, desde o começo até o fim, escrita. Neste caso, os arquivos fundam a primeira escrita com a qual a história se depara, antes da própria história se transformar em possibilidade literária. Todavia, é difícil estabelecer um começo para o pensar histórico, uma vez que esse, quando compreendido com uma temporalização da experiência comum, torna-se indefinivel. Recorrendo a Gramatologia, de Jacques Derrida, Ricoeur escreve: "os homens espaçaram seus signos, ao mesmo tempo - se isto tem algum sentido - em que os encadearam ao longo da continuidade temporal do fluxo verbal" (2007, p. 149). E por isso a impossibilidade de se encontrar o início da escrita da história. Nesse sentido, a história não cessa de "nascer do distanciamento em que se embasa o recurso para exterioridade do rastro arquival" (2007, p. 149).

Tal discussão em torno do passado e as imagens que se anunciam no presente, torna igualmente importante a ideia de fantasma. Em seu livro Espectros de Marx, Jacques Derrida analisa os procedimentos fantasmáticos em Shakespeare e Marx, demonstrando uma interlocução entre as obras dos dois autores. De acordo com o filósofo, a "experiência do espectro", como Marx terá pensado, descrito ou diagnosticado, faz parte de uma determinada dramaturgia da Europa moderna, "principalmente a de seus grandes projetos unificadores" (DERRIDA, 1994, p. 19). Também, na esteira de "uma memória filial, Shakespeare terá frequentemente inspirado essa teatralização marxiana" (DERRIDA, 1994, p. 19). Na sequência, Derrida interroga-se: "o que vem a ser um fantasma?" Para o autor, um fantasma é sempre "retornante". Nesse sentido, "não se tem meios de controlar suas idas e vindas porque ele começa por retornar" (DERRIDA, 1994, p. 27). Na abordagem do romance de Luís Cardoso, evidenciam-se traços fantasmáticos oriundos da personagem Coronel Santiago, pai do protagonista. A morte do coronel é o enigma que move os pensamentos de Lucas Santiago.

A última morte do coronel Santiago erige-se a partir das rememorações e peripécias do jovem escritor Lucas Santiago que vive exilado em Lisboa. Filho de uma figura emblemática do Timor-Leste, a personagem recorda seus primeiros anos em Lisboa, quando fora mandado pelo pai para estudar medicina na metrópole. Nascido no Timor, Lucas encontra-se afastado do país de origem há 25 anos. Em que pese tal ausência, a terra natal continua a fustigá-lo, influenciando atitudes, elevando seus questionamentos e angústias. 
O passado ecoa em todos os passos da personagem. É uma força que a habita, estruturando-a, consciente e inconscientemente. Os temores se voltam sempre para a pátria abandonada. Contribuem para a permanente inquietação a formação católica ${ }^{5}$ e a presença-ausência paterna. A presença fantasmática do pai, preenchendo-a com a criação de figuras exiladas, presentes nos romances publicados por Lucas Santiago, é outro aspecto fundamental. Esta se constitui na principal lembrança do filho, imperativo categórico do retorno à casa familiar. Em seu exílio em Lisboa, opta por escrever ficção, transformandose esta em uma espécie de mecanismo de sobrevivência psíquica e material.

Para compreender a natureza do escritor diaspórico no romance de Luís Cardoso, associo-o, como exemplo, às palavras proferidas pela personagem Mwadia Malunga, presente em 0 outro pé da sereia, de Mia Couto. A esposa do camponês Madzero, em conversa com o curandeiro Lázaro Vivo, sentencia: "inventaria vidas para preencher o vazio do seu coração natal" (COUTO, 2006, p. 47). A manifestação de Mwadia reflete a condição existencial de Lucas Santiago que, ao se tornar escritor reconhecido no exílio, procura contornar a ausência da terra natal.

A experiência do escritor exilado que vê na escrita uma forma de reflexão e sobrevivência encontra-se presente em dois importantes pensadores: Adorno e Edward Said. Ambos escrevem sobre tal fenômeno. O primeiro chama a atenção para a escrita como a casa metafórica do intelectual exilado. A categoria do exílio alimenta igualmente as reflexões de Said, ele também um exilado de outro lugar e tempo. Segundo Said, o intelectual deve ser caracterizado como "um exilado e marginal, como amador e autor de uma linguagem que tenta falar a verdade ao poder" (SAID, 2005, p. 15). É uma condição solitária, porém melhor do que uma "tolerância gregária para o estado de coisas" (SAID, 2005, p. 17).

No ensaio Reflexões sobre o exillio, Said tece considerações acerca dessa "fratura incurável" que se dá "entre um ser humano e um lugar natal" (2003, p. 46) quando estes se veem separados um do outro. A condição do exilado é percebida sob distintas perspectivas que acabam por convergir para a questão da formação identitária deste sujeito que se vê de alguma maneira incluído e, paradoxalmente, excluído da terra de origem. Said dá ênfase à vida dos escritores exilados e para o sentimento de abandono daquele que vai para o degredo. Em vista disso, descreve as mazelas do ser que se exila, que passa a conviver, através de tal experiência, com uma série de problemas, no sentido de que o exilado não encontra mais referentes nem vínculos culturais que contribuam para a constituição do seu ethos.

${ }^{5} \mathrm{O}$ olhar de Lucas é mediado sempre pela estátua de Cristo, situada na encosta da travessia da Ponte Vinte e Cinco de Abril ou ao mirar o Corcovado carioca, ou ainda nas lembranças das aulas na Escola Colonial Católica no Timor. 
Tal discurso vem ao encontro do sentimento de não-pertença ao qual o sujeito não encontra mais identificação ao lugar de onde veio e nem para onde foi. A condição de entre-lugar passa a figurar os sentimentos do exilado que vive numa espécie de descontinuidade, oposta à fixidez das raízes do nacionalismo. Para exemplificar tal sentimento de não-pertença, Said utilizar-se-á de exemplos comuns ao leitor, porque historicamente bem marcados: judeus, palestinos, árabes - povos que, retirados de suas terras, vivem em países estranhos onde já consolidaram sua identidade, mas ainda assim vivem um sentimento constante de deslocamento. É através da memória que o exilado procura preservar as características da terra natal, desejando manter vivas as lembranças dos lugares em que vivera, embora hoje, num provável retorno, tal origem Ihe traga mais estranhamento do que familiaridades.

Em Cultura e imperialismo (1991), Said chama de viagem para dentro aquele esforço desenvolvido por muitos intelectuais, escritores e críticos do mundo periférico, através de suas obras, em mostrar à Europa e ao Ocidente, as figuras marginalizadas e suprimidas da História. Trata-se de um empenho consciente para "ingressar no discurso da Europa e do Ocidente, para se misturar a ele, transformá-lo, fazendo com que sejam reconhecidas as histórias marginalizadas, suprimidas ou esquecidas" (SAID, 1999, p. 274). Destaca, por exemplo, o trabalho literário de Salman Rushdie, enquanto "escrita da resistência", uma obra brilhante, baseada na "imaginação libertadora da própria independência, com todas as anomalias e contradições" (SAID, 1999, p. 274).

Verifica-se a metáfora da viagem para dentro na narrativa $A$ última morte do coronel Santiago, de Luís Cardoso, em que o próprio autor vivencia a experiência do deslocamento, assim como sua personagem. Tal obra elucida as observações desenvolvidas até aqui. 0 romance evoca múltiplos territórios que se sobrepõem e se entrelaçam, informando equações históricas geradas por impérios e colônias. Tal movimentação e pluralidade resultam em processos de hibridação, revestidos de euforia e desalento. ${ }^{6}$ Tal dimensão pode ser entrevista na fala do narrador, filho de um coronel timorense que apoiava o domínio imperial português: "Nunca se sabe, coronel Santiago, as partidas que uma identidade pode pregar" (CARDOSO, 2003, p. 11). O bordão, que é repetido com frequência, dimensiona perfeitamente as diretrizes predominantes do enredo: uma crise política e identitária que dilacera as personagens do livro.

\footnotetext{
${ }^{6}$ Tomando como referência tal risco, o sociólogo português Boaventura de Sousa Santos adverte para certa euforia do discurso pós-colonial que, ao celebrar a condição híbrida diaspórica, esquece que a mesma tem sido utilizada "para ocultar as realidades imediatas, econômicas, sociais, políticas e culturais dos imigrantes ou das comunidades diaspóricas" (SANTOS, 2006, p. 240). Para o autor, "a celebração da diáspora e o enaltecimento da estética da hibridez tendem a ocultar os conflitos sociais reais em que os grupos imigrantes envolvidos, e sempre em posições de poder que lhe são desfavoráveis, como é o caso tangente da diáspora muçulmana no Ocidente" (SANTOS, 2006, p. 240).
} 
Exilado, Lucas é assombrado por fantasmas, vozes e cheiros do passado que, ora inviabilizam, ora protegem sua existência. De outro modo, tais percepções impedem que se entregue plenamente às situações do presente. Os amores vividos não aplacam o tormento impresso pelas lembranças. As imagens da morte rondam-no constantemente. Escrever torna-se uma das únicas armas para combater a solidão e as ausências, afugentando os apelos suicidas.

Em meio aos projetos literários, com algumas publicações bem recebidas pela crítica, Lucas revela pequenas histórias do cotidiano lisboeta, assinalado pelo ritmo metropolitano veloz. Ou ainda, emocionase pelas narrativas dos imigrantes africanos, residentes na periferia da cidade.

No livro, uma Lisboa multicultural, cercada pelo preconceito, mas também pela solidariedade, dota a capital portuguesa de um espetáculo múltiplo e desigual que estimula a criação ficcional. Personagens do cotidiano lisboeta mesclam-se aos seres de papel inventados por Lucas, confundindo-se com as ações vivenciadas pelo escritor. ${ }^{7}$

De outro modo, as evocações literárias, manifestadas nas citações de obras e textos de importantes escritores, bem como no comentário acerca de filmes e diretores cinematográficos parecem acomodar a dor, partilhando com tais formas o prazer, as dificuldades e a emoção do fazer artístico. 0 argentino Jorge Luís Borges transforma-se numa espécie de bússola artística, sendo referido com frequência. Os convites para participar em congressos causam temor e irritabilidade quando lhe perguntam acerca do seu país de origem.

A associação com o pai, um ardoroso defensor do colonialismo português e admirador de Salazar, irrita o escritor:

Mas também o que é que se poderia esperar de um filho de coronel de segunda linha que era um convicto devoto de Salazar. Nunca participou em nenhuma manifestação ou fez vigílias e tendo mesmo feito confidências em privado que Timor não constava no seu roteiro de viagens absorto que estava em descobrir outros caminhos de pedra (CARDOSO, 2003, p. 41-42).

Igualmente o perturbam as cobranças feitas pelas forças políticas de libertação de seu país que Ihe exigiam que escrevesse sobre os heróis de sua terra, fato que, segundo Lucas Santiago, o protagonista de seu primeiro livro eximiu-se de fazer. Assim:

\footnotetext{
7 É o caso da personagem Margarida, uma jovem angolana imigrante que serve de mote para a construção de uma personagem
} de um livro em processo de finalização. 
Acusavam-no de ter sido conivente com o genocídio do seu povo tal como o Sextafeira, o protagonista do seu romance que, aceitando a sua condição de servo que the garantia uma falsa prosperidade, permaneceu durante todos esses anos indiferente ao sofrimento dos seus conterrâneos, investido que estava na protecção do seu bom nome (CARDOSO, 2003, p. 41).

Ainda que questionado acerca de um posicionamento mais firme em relação à presença portuguesa e indonésia no Timor, em um dos eventos, a crítica literária "reagiu com fervor e entusiasmo ao aparecimento de um novo escritor lusófono, uma versão mais atualizada do termo ultramarino" (CARDOSO, 2003, p. 40). Aliás, ele "preferia o termo ultramarino", uma vez que a expressão expunha uma verdade intransponível: "havia um mar entre um e outro que os separava e tinha de se navegar muito para encurtar o tempo e reduzir a distância" (CARDOSO, 2003, p. 40).

No curso da salvação identitária, outras personagens impulsionam Lucas a tomar decisões, restituindo-Ihe um clima mais eufórico frente aos atropelos e tormentos da vida passada. Assim, duas mulheres animam o escritor, ora partilhando suas biografias familiares, ora entregando-se de corpo e alma aos desejos contidos do poeta. Uma é Clara, uma migrante timorense das montanhas de Maubisse, que conhecera na Faculdade de Medicina. Enquanto colegas, ambos percorrem a Europa, vivendo uma intensa paixão juvenil. Incapaz de dar prosseguimento àquele relacionamento, Lucas, além de abandonar a faculdade, afasta-se da moça. Reencontra-a, anos depois, num quarto de hospital onde fora levado após um acidente de automóvel. Ela, agora, encontra-se casada e atua como médica. No breve contato, Clara8 é categórica: Lucas deve retornar à terra natal, casando-se com alguém do lugar. Embora um reencontro comovente, a médica impacienta-se com o amigo devido a seu medo e covardia, pensando sempre na morte, consumindo-se em pensamentos tristes:

Não fiques com remorso do que fizeste há mais de vinte anos. Estás sempre com as despesas do passado nas tuas costas. Das que não te pertencem e das que julgas que te pertencem. Devias chorar porque não tens força para te armares em forte. Quebra-te facilmente. Depois guardas os cacos dentro de ti. Ficas como um castelo que se arruinou por dentro. Por que escolhes sempre um beco sem saída? Não compreendo essa tua obsessão pela morte (CARDOSO, 2003, p. 123).

Sugere, por fim, que concorra a uma Bolsa Literária, apresentando um projeto. Desta forma, conciliaria o gosto pelo escrever e a volta ao país de origem. Lucas anima-se, seguindo o conselho.

\footnotetext{
${ }^{8}$ Clara pede a Lucas um favor quando de sua chegada a Timor: que escrevesse cartas, relatando sobre a Vila de Maubisse onde ela nascera. Embora Clara esteja "adaptada" em Lisboa, a recomendação é uma alusão evidente à saudade do país.
} 
Outra personagem feminina de realce na interlocução com Lucas é a angolana Margarida, filha de um ex-ferroviário, e atualmente empresário da construção civil em Lisboa. Participa de um grupo musical denominado Margem Infinita. Ela canta, Lucas toca clarinete. Partilham igualmente as mesmas dores dos exilados e emigrados que sentem o abandono pátrio. Margarida se refaz cantando e pintando. Cursa a Faculdade de Belas-Artes, porém, tal como Lucas, o fantasma do passado a persegue, inquirindo sempre sobre a sua identidade:

Estudava pintura nas Belas-Artes. Queria ser pintora para captar com as mãos o que os olhos não conseguiam trazer à luz do dia, o que se escondia para lá da vista, a quem um dia chamaram alma. Sentava-se em frente do espelho dias seguidos e horas intermináveis em busca de um único traço onde se reencontrasse. Nunca pintou ninguém senão ela própria. Procurava conhecer essa entidade que a levava pelos sítios mais remotos da sua imaginação. Por mais tentativas que fizesse nenhuma a satisfez (CARDOSO, 2003, p. 75).

Do universo timorense, destaque para a personagem Pontiana, a moça oferecida a Lucas quando regressasse da Europa; há ainda o padre Agostinho, que procurava convencê-lo da importância do cristianismo agostiniano. A primeira aparecia-lhe sempre em sonho; o segundo, embora divergindo do comportamento do escritor, ampara-o ao criar oportunidades de trabalho. Em relação à mãe, as referências são mínimas, ocorrendo no primeiro capítulo, em que o narrador se dedica a comentar sobre a vida do coronel Pedro Santiago, seu pai:

Pedro Santiago casou-se muitos anos depois com pompa e circunstância com dona Juliana, mandada vir de um colégio interno de freiras, perante a insistência popular que Ihe exigia um descendente proveniente de um matrimônio selado entre duas famílias importantes e abastadas. Nada quis saber dos filhos que foi tendo por conta própria. Foram-se perdendo na multidão dos anônimos. Uns entre tantos e nem se importavam que Ihes chamassem bastardos. Também se tinham esquecido dele, do pai que não tinham, um pai abastardado, tão bem tratados que estavam pelas novas famílias que os acolheram. Quando viu o filho legitimo pela primeira vez chamou-Ihe Lucas perante o espanto da mulher como se tivesse reconhecido no recém-nascido um velho camarada (CARDOSO, 2003, p. 10).

Desde o nascimento, o filho torna-se a expressão concreta dos sonhos não realizados do coronel. Desses sonhos, três ocorrem talvez de maneira involuntária: uma visita à cidade de Santiago de Compostela; uma viagem à metrópole portuguesa; e o surgimento de um escritor que escrevesse acerca da genealogia familiar. Mesmo que recuse a associação ao pai, Lucas cumpre tal destino quando ainda não estava apto para compreendê-lo. 
Os laços de identificação são mais intensos que as tentativas de sonegação. Com o passar dos anos, Lucas sente-se cada vez mais prisioneiro do passado, incapaz de esquecê-lo, ajustando-se a si as maneiras da personagem paterna. Do retorno à terra natal até o pungente deitar-se sob o túmulo onde o pai fora sepultado, o escritor se vê preso à formação familiar. Desta forma, o fantasma de Pedro Santiago torna-se quase real. A "conversão" identitária do filho é uma das passagens comoventes do romance.

Contrariado com as cerimônias locais, levadas a cabo em virtude de sua presença, aos poucos, Lucas incorpora o ritmo do lugar, assentando-se à tradição. Surpreende-se vestido com o velho terno de linho branco, cujos furos das balas que o coronel levara de Pedro Raimundo, o fiel filho adotivo, apareciam agora cerzidos pela empregada Prudência. Do uso do rapé aos cumprimentos dos criados, reconhecendo-o como um antepassado familiar importante, era apenas mais uma etapa que, por certo, resultaria na fixação do escritor naquele espaço:

Encontrou em cima da sua cama o velho fato de linho branco do coronel. Sentou-se na cama para examinar aquela roupa que só poderia ser do seu pai. Notou que os enormes buracos que deveriam existir depois daquelas rajadas já lá não estavam. A velha Prudência tinha cerzido com linha branca e dava-Ihe um ar de enfeite que the apetecia tocar com os dedos das mãos. Encontrou a cigarreira colocada ao lado do fato branco. Destapou-a e viu que estava enchida com tabaco de rapé. Colocou um bocado na palma da sua mão e passou pelas narinas. Tinha um cheiro diferente. Bastante forte. Com um dedo da mão fechou uma narina e com a outra inalou lentamente. Uma pequena tontura foi tomando conta do corpo dele. Depois nunca mais se lembrou de nada. Passado algum tempo levantou-se da cama e foi-se juntar aos restantes familiares que o esperavam. Sem ele dar por isso alguém fez o obséquio de lhe mudar a roupa enquanto dormia. Quando acordou estava vestido com o velho fato do coronel Pedro Santiago. Quando se apresentou na sala houve um terrivel silêncio que se abateu sobre as pessoas. Ficaram calados como se um fantasma ou morto tivesse sido convidado para as suas próprias cerimônias fúnebres. Primeiro viu nos olhos dos presentes uma estupefacção. Depois um profundo respeito e contenção. Foram-se aproximando dele, curvavam-se e beijavam-Ihe a mão que desta vez não recusou, para a sua surpresa (CARDOSO, 2003, p. 255).

Ao vestir o terno do pai, ao repetir seus gestos, ao experimentar chás e fumos consumidos pelo coronel, ao ser aclamado pelos nativos, em especial os empregados e moradores da região, ao visitar o monte Manumera, assinalado pela beleza das montanhas, Lucas refaz o percurso de sua formação, fundamental para o entendimento de sua personalidade e identidade. Para tanto, cruzou uma longa travessia, marcada por múltiplos mundos culturais, excluído da pátria, família e filhos. Sem profissão definida, sentindo-se, ao mesmo tempo, livre e algemado ao passado. O retorno contamina o sujeito, incapaz de se insurgir contra o peso da história. Morrer, ali, é a única alternativa. É o fim da travessia. 
A última morte do coronel Santiago é um romance que aborda a memória do deslocar-se. Explora, igualmente, os efeitos da fragmentação identitária que busca o permanente reencontro. Numa bela passagem em Locais da cultura, Homi Bhabha escreve: "Quando a visibilidade histórica já se apagou, quando o presente do indicativo do testemunho perde o poder de capturar, aí os deslocamentos da memória e as indireções da arte nos oferecem a imagem de nossa sobrevivência psíquica" (1998, p. 42). Pode-se conferir tal observação de Bhabha no romance de Luís Cardoso em que a obra de arte literária, através de suas obliquidades estético-estilísticas, nos dá "olhos para ver e para chorar", recorrendo à memória assombrada para fazer ressurgir as vozes oprimidas pela arbitrariedade e o silêncio da História. ${ }^{9}$

Estilhaçado pela história nacional, pelas fraturas familiares e amorosas, a personagem encontra na escrita o meio para suportar ausências, segredos e violações. A escrita é o solo adotado para compreender a si e aos outros.

O caminhar por diferentes lugares, procurando respostas para as inquietações existenciais, é o projeto inicial do romancista diaspórico. Viajar, sem ancorar, parece ser o seu destino. Todavia, o chamamento permanente, através da memória, denota um encanto por seu país, ainda que tal encantar venha assinalado pelo sofrimento, exposto em longos anos de violência colonial e dificuldades econômicas. Pode-se, então, traduzir o romance de Luís Cardoso numa dimensão dialética assinalada entre o partir e o ficar, constituindo-se tais configurações em emblemas da identidade do sujeito timorense, fruto das relações coloniais que sempre limitaram historicamente aquela região.

Romances como os construídos por Luís Cardoso reivindicam um novo posicionamento no concerto das relações de poder literário e político em âmbito internacional. Em um mundo que se alterou de maneira drástica, proporcionando novas consciências geográficas, pensar neste mesmo mundo a partir

\footnotetext{
9 Nessa perspectiva, Ricoeur chama a atenção para a importância da ficção na defesa do tremendum horrendum, revelador de uma comemoração ao contrário. Segundo o filósofo francês, o papel da ficção nessa "memória do horrível é um corolário do poder do horror", exercendo sobre a consciência histórica uma função específica de individuação. Na rememoração do horrível, a narrativa de ficção tem a força de provocar uma ilusão de presença, no entanto, controlada pelo distanciamento crítico. 0 controle da ilusão pela ficção não se destina ao entretenimento, visando à reflexão e consciência históricas através da "individuação pelo horror". Para Ricoeur, por mais elevados e profundos que sejam os sentimentos trazidos à luz pela memória do horror, esses "permaneceriam cegos sem a quase-intuitividade da ficção" que "dá olhos ao narrador horrorizado, olhos para ver e chorar" (RICOEUR, 1997, p. 327).
} 
de um único centro de legitimação estético-cognitivo demonstra apenas o desperdício das experiências interculturais. ${ }^{10}$ Para Said (2002):

Ao longo da história, a geografia do mundo mudou tanto que é quase impossivel tentar conciliações entre história e literatura sem levar em conta as novas e complexas variedades de experiências históricas disponiveis para nós no mundo pós-eurocêntrico de hoje (SAID, 2003, p. 225-226).

A obra do escritor timorense mobiliza uma nova consciência geográfica, descentrada e multifacetada. A descentralidade está no desabrochar da nova literatura e na revelação de culturas que se cruzam, fruto do colonialismo, das migrações, das deportações, dos êxodos e exílios, da presença de viajantes e aventureiros. Tais deslocamentos proporcionam múltiplos contatos que, derivados de extensas travessias transcontinentais, rápidas ou demoradamente vividas, dilatam a possibilidade de conhecer a diversidade do mundo.

Nesse sentido, a ficção de Luís Cardoso acaba por expor o caráter mundial da literatura, quando as diferenças e peculiaridades culturais e históricas projetadas pela critica pós-colonial buscam reposicionar as relações de poder do campo literário. Neste caso, uma visão contrapontística, como defende Said, é significativa, uma vez que, por meio dela, processam-se os embates entre o local e o global, indicando que, através das travessias e encontros, forja-se o ambiente da razão crítica multicultural, e esta estimularia um mundo policêntrico e plural. Neste universo, as hegemonias literárias seriam resultados, não do fundamentalismo mercadológico, mas de produções culturais polifônicas como expressão de um novo bem simbólico mundial, a solidariedade universal.

\footnotetext{
${ }^{10}$ Para Boaventura de Sousa Santos, um dos fatores geradores do desperdício de experiências está na "edificação de impérios coloniais" que implicou na "transladação, para as colônias, dos modos de vida ditos civilizados". Segundo o sociólogo português, "o colonialismo, forjado enquanto conceito epistêmico na época imperial, continua hoje a ser sinônimo de empobrecimento de saberes, na medida em que promove a guetização dos saberes, obliterando outras formas de conhecimento, isto é, a produção e transmissão de experiências" (2009, p. 30).
} 


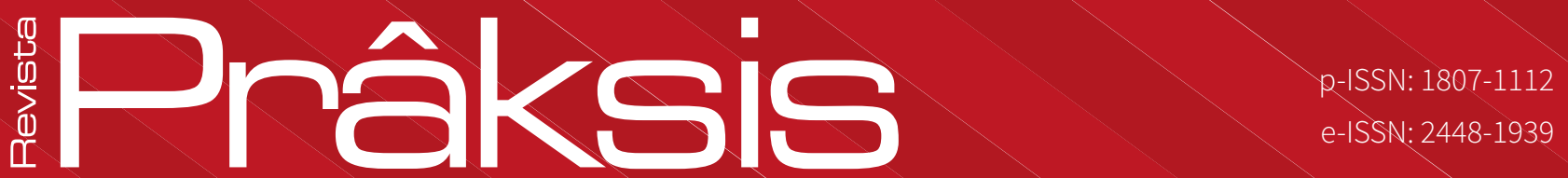

\section{REFERÊNCIAS}

BHABHA, Homi. O local da cultura. Belo Horizonte: UFMG, 1998.

CARDOSO, Luís. A última morte do coronel Santiago. Lisboa: Dom Quixote, 2003.

RICOEUR, Paul. A memória, a história, o esquecimento. Campinas; SP: Unicamp, 2007.

Tempo e narrativa. Campinas; SP: Papirus, 1997.

SAID, Edward. Cultura e imperialismo. São Paulo: Companhia das Letras, 1999.

Representações do intelectual. São Paulo: Companhia das Letras, 2005.

Reflexões sobre o exílio e outros ensaios. São Paulo: Companhia das Letras, 2003.

RAMA, Ángel. Literatura e cultura na América Latina. São Paulo: Edusp, 2001.

SANTOS, Boaventura de Sousa. A gramática do tempo. São Paulo: Cortez, 2006.

SANTOS, Boaventura de Sousa; MENEZES, Maria Paula (Org.). Epistemologias do sul. Coimbra: Almedina, 2009. 